Orthopäde 2021 · 50:700-712

https://doi.org/10.1007/s00132-021-04072-1

Angenommen: 21. Januar 2021

Online publiziert: 22. Februar 2021

๑ Der/die Autor(en) 2021

\section{Die Labordiagnostik stellt in der medizinischen Betreuung von Leistungssportlern eine wichtige di- agnostische Säule dar. Dabei können mithilfe geeigneter Laborparame- ter essenzielle Informationen zur Beurteilung der Leistungs- und Re- generationsfähigkeit von Athleten gewonnen werden. Weiterhin ist die Labordiagnostik sowohl in der Prä- vention als auch in der Diagnostik und Rehabilitation von Verletzun- gen von Bedeutung. Insbesondere liegt der Fokus auf dem Erkennen und Ausgleich von Mangelzustän- den. Diesem Präventionsgedanken muss angesichts der immer grö- Ber werdenden Trainings- und Wettkampfbelastungen im Spit- zensport eine hohe Bedeutsamkeit zugeschrieben werden.}

Die verschiedenen im Blut messbaren Biomarker liefern reproduzierbare, objektive, wertvolle und valide Informationen über biologische Prozesse und Krankheitszustände. Neben den klassischen hämatologischen Werten werden zunehmend auch muskuloskelettale Biomarker zur Analyse genutzt, welche adäquat mess- und analysierbar sind und Hinweise auf sowohl physiologische als auch pathologische Prozesse des muskuloskelettalen Systems bieten. Ziel dieser Arbeit ist die Übersicht einer praxisrelevanten muskuloskelettalen Labordiagnostik, welche relevante Infor-

Maximilian M. Delsmann' • Julian Stürznickel' · Michael Amling' •

Peter Ueblacker ${ }^{2}$. Tim Rolvien ${ }^{3}$

'Institut für Osteologie und Biomechanik, Universitätsklinikum Hamburg-Eppendorf, Hamburg, Deutschland

${ }^{2}$ Praxis für Orthopädie und Sportmedizin, München, Deutschland

${ }^{3}$ Fachbereich Orthopädie, Klinik und Poliklinik für Unfallchirurgie und Orthopädie, Universitätsklinikum Hamburg-Eppendorf, Hamburg, Deutschland

\title{
Muskuloskelettale Labordiagnostik im Leistungssport
}

mationen für die ärztliche Betreuung von Leistungs- und Spitzensportler liefern soll.

Die Erkenntnisse sollen Athleten und Betreuer auf dem Weg zu einer höchstmöglichen Leistungsfähigkeit und bestmöglichen Prävention von Verletzungen unterstützen. Beispielsweise konnte die klinische Relevanz einer strukturiert durchgeführten Labordiagnostik bei männlichen Athleten einer professionellen amerikanischen Sportmannschaft aufgezeigt werden, welche über 9 Jahre im Rahmen der Saisonvorbereitung durchgeführt wurde. Bei $10 \%$ der Athleten wurden pathologische Laborwerte detektiert, welche wiederum bei $40 \%$ weiterführende Laboruntersuchungen erforderlich machten [1]. Die vorliegende Arbeit liefert einen Überblick über die wichtigsten laborchemischen Parameter in der muskuloskelettalen Diagnostik hinsichtlich 1) des Knochenstoffwechsels, 2) des Muskelstatus und 3) der Ernährung (• Abb. 1). Obwohl Verletzungen der Sehnen (Tendinopathien, Enthesiopathien und Rupturen) eine große Rolle bei Athleten spielen [2] und die Labordiagnostik diesbezüglich einen wissenschaftlichen Stellenwert hat, spielt sie jedoch in der klinischen Diagnostik aktuell eine untergeordnete Rolle und wird somit in diesem Artikel nicht beleuchtet.

\section{Knochenstoffwechsel}

Für Leistungssportler mit hohen körperlichen Belastungen ist ein intakter Knochenstoffwechsel von essenzieller Bedeutung. Der Knochen bildet als Endoskelett neben der Muskulatur, den Sehnen

\begin{tabular}{|ll}
\hline Abkürzungen \\
\hline$A D P$ & Adenosindiphosphat \\
\hline$A L A T$ & Alanin-Aminotransferase \\
\hline$A P$ & Alkalische Phosphatase \\
\hline$A S A T$ & Aspartat-Aminotransferase \\
\hline$A T P$ & Adenosintriphosphat \\
\hline$B A P$ & "Bone-specific alkaline phospha- \\
\hline$B M D$ & "Bone mineral density" \\
\hline$C K$ & Kreatinkinase \\
\hline$D P D$ & Desoxypyridinolin \\
\hline$F G F$ & "Fibroblast growth factor" \\
\hline$I S S N$ & "International Society of Sports \\
\hline Nutrition"
\end{tabular}


und Bändern das Hauptorgan des Bewegungsapparates. Er garantiert die $\mathrm{Be}$ weglichkeit und Stabilität und unterliegt ständiger Adaptation. Mittels labordiagnostischer Parameter, welche sich als Marker des Knochenumbaus („remodelings") und der Mineralstoffhomöostase eignen, lässt sich neben apparativen diagnostischen Methoden der metabolische Knochenstatus des Athleten abbilden [3].

Die Knochenmineralisation wird maßgeblich über die Calciumhomöostase reguliert. Die empfohlene Tagesaufnahme von Calcium beträgt 1000 $1500 \mathrm{mg} /$ Tag $[4,5]$. Neben Calcium ist Phosphat als Mineralstoff ebenfalls maßgeblich an der Mineralisation des Knochens beteiligt. Bei nicht ausreichender Versorgung des Körpers mit Calcium und/oder Phosphat resultiert eine reduzierte Knochenmineralisation bis hin zur Osteomalazie, begleitet von einer muskulären Insuffizienz [6, 7]. Chronische Hypophosphatämien können vielfältige Ursachen haben und entstehen beispielsweise durch Mangelernährung (v. a. Anorexia nervosa), in Zusammenhang mit Vitamin-D-Mangel, bei genetischen Erkrankungen (v.a. Phosphatdiabetes), paraneoplastisch (v.a. onkogene Osteomalazie) oder medikamentenassoziiert (u. a. Antazida, Diuretika) [6].

Von übergeordneter Bedeutung für den Knochenmetabolismus und die Knochenfestigkeit sind das Steroidhormon Calcitriol $\left(1,25(\mathrm{OH})_{2}\right.$-Vitamin- $\left.\mathrm{D}_{3}\right)$, das Parathormon (PTH) sowie der „fibroblast growth factor" 23 (FGF23), welche die Hauptregulatoren der Calcium- und Phosphathomöostase darstellen [8-10]. Calcitriol steigert als aktiver Metabolit des Vitamin $\mathrm{D}_{3}$ (Cholecalciferol) die intestinale und renale Resorption von Calcium, erhöht somit die Calciumkonzentration im Körper und führt zu einer Mineralisation unmineralisierter Knochensubstanz (Osteoid) [11]. Bei einem Vitamin-D-Mangel und konsekutiver enteraler Calciumaufnahmestörung kann durch eine kompensatorisch gesteigerte PTH-Sekretion (sekundärer Hyperparathyreoidismus) eine Stimulation der knochenresorbierenden Osteoklasten und somit eine vermehrte Calciummobilisation aus dem Knochen induziert werden. Dies findet auf Kosten der
Knochenqualität statt und kann durch eine Reduktion des Knochenmineralsalzgehaltes und der Knochenstruktur $\mathrm{zu}$ einer Verschlechterung der Knochenstabilität führen [12]. Ein weiterer häufiger Grund für eine gestörte enterale Calciumaufnahme ist die (chronische) Einnahme von Protonenpumpeninhibitoren mit konsekutiver Hypochlorhydrie [13]. Ferner wird in diesem Zustand die renale Phosphatelimination gesteigert, $\mathrm{da}$ ein erhöhter Phosphatspiegel wiederum einem Calciumanstieg entgegenwirken würde. Eine erhöhte PTH-Konzentration bei gleichzeitig erhöhtem Calciumspiegel spricht hingegen für eine autonome Überfunktion der Nebenschilddrüse im Sinne eines primären oder tertiären (Folge einer chronischen Überstimulation nach sekundärem) Hyperparathyreoidismus [9]. FGF23 ist ein endokrines Hormon, welches eine Phosphaturie in der Niere verursacht, während die Produktion von Calcitriol gehemmt wird [10]. Die laborchemische Bestimmung von FGF23 stellt aktuell noch keine Routinediagnostik dar, ist jedoch bei rezidivierenden Hypophosphatämien und Verdacht auf eine genetische oder erworbene Phosphatstoffwechselstörung indiziert.

Die klinische Relevanz von Vitamin D ist in der sportmedizinischen Betreuung von Leistungs- und auch Gelegenheitssportlern hoch, da Vitamin D aufgrund einer direkten oder indirekten Beeinflussung der Leistungs- und Regenerationsfähigkeit sowie des Verletzungsrisikos, wie für ossäre Stressreaktionen, einen maßgeblichen Effekt auf die Gesundheit des Athleten haben kann [14-16]. Dennoch stellt ein Vitamin-D-Mangel im professionellen Sport ein häufig auftretendes Phänomen dar [1, 17-20]. So konnte bei 13 von 20 männlichen Profifußballern des englischen PremierLeague-Teams Liverpool FC im Dezember 2010 ein insuffizienter Vitamin-DStatus erhoben werden [17]. Auch bei 31 von 70 männlichen Handballspielern aus der ersten deutschen Handballiga konnte ein Vitamin-D-Mangel festgestellt werden [18]. Dieser Mangel ist nicht nur ausschließlich in den Wintermonaten oder bei Hallensportlern, sondern über das ganze Jahr hinweg und auch bei anderen Sportarten zu beobachten. So zeigten lediglich 25 von 80 Footballspielern der National Football League (NFL) im Rahmen der routinemäßigen Gesundheitsuntersuchungen während der Saisonpause und in der Vorbereitungsphase adäquate Vitamin-D-Spiegel, wobei das Risiko für einen Vitamin-DMangel bei dunkelhäutigen Athleten erhöht war [19]. Hierbei ist zu bedenken, dass eine derart hohe Prävalenz an Mangelzuständen trotz in den Vereinigten Staaten teilweise mit Vitamin D angereicherter Lebensmittel vorlag [21]. Ein optimaler Referenzwert für Vitamin D bei Leistungssportlern ist Gegenstand von Diskussionen [7, 14, 15, 22, 23]. Zur Beurteilung, ob ein Athlet oder eine Athletin ausreichend mit Vitamin D versorgt ist, wird in der Regel das Calcidiol (25(OH)-Vitamin-D3) im Serum gemessen. Zunächst konnte auf histologischer Ebene in der Allgemeinbevölkerung gezeigt werden, dass ein Vitamin-D-Spiegel $\left(25(\mathrm{OH}) \mathrm{D}_{3}\right)$ von $\geq 30 \mathrm{ng} / \mathrm{ml}$ bei Frauen und Männern eine Hypomineralisation im Sinne einer Osteomalazie weitestgehend ausschließt [7]. Während bei Vitamin-D-Konzentrationen von $\geq 40 \mathrm{ng} / \mathrm{ml}$ von einem präventiven Nutzen bezüglich (Stress-)Frakturen auszugehen ist, scheint ein Spiegel von $\geq 50 \mathrm{ng} / \mathrm{ml}$ für beide Geschlechter eine optimale Voraussetzung für eine maximale Leistungsfähigkeit der Athleten darzustellen [22]. So konnten Williams und Kollegen in verschiedenen amerikanischen Männer- und Frauenprofiteams (Crosslauf, Basketball, Fußball, Leichtathletik) zeigen, dass durch eine 8-wöchige Vitamin-D-Supplementation mit 50.000 IE pro Woche bei Vitamin-D-insuffizienten Athleten $(<30 \mathrm{ng} / \mathrm{ml})$ eine Reduktion der Inzidenz von Stressfrakturen von $7,5 \%$ auf $1,6 \%$ erzielt werden konnte [14]. Auch bei 5201 untersuchten weiblichen Navy-Rekruten konnte unter Calcium(2000 mg/Tag) und Vitamin-D-Supplementation (800 IE/Tag) eine um $21 \%$ geringere Inzidenz für Stressfrakturen festgestellt werden [16]. Umgekehrt war in einem Kollektiv von 53 Patienten mit Stressfrakturen bei 44 Betroffenen (83\%) ein Vitamin-D-Spiegel von $<40 \mathrm{ng} / \mathrm{ml}$ zu beobachten [15]. 
Orthopäde 2021·50:700-712 https://doi.org/10.1007/s00132-021-04072-1

(c) Der/die Autor(en) 2021

M. M. Delsmann · J. Stürznickel · M. Amling · P. Ueblacker · T. Rolvien

\section{Muskuloskelettale Labordiagnostik im Leistungssport}

\section{Zusammenfassung}

Hintergrund. Die labordiagnostische

Untersuchung stellt eine wichtige Möglichkeit

zur Beurteilung und Optimierung der

Leistungs- und Regenerationsfähigkeit professioneller Athleten dar. Ferner ist sie für die Prävention, Diagnostik und Rehabilitation von Verletzungen und Überbelastungen von Bedeutung.

Fragestellung. Ziel dieser Arbeit ist die Darstellung muskuloskelettaler laborchemischer Parameter, die relevante Erkenntnisse für die medizinische Betreuung von Leistungssportlern liefern.

Material und Methoden. Literaturrecherche und narratives Review.

Ergebnisse. Die Bestimmung des VitaminD-, Calcium- und Knochenstoffwechsels stellt die laborchemische Basisdiagnostik im
Rahmen der Beurteilung des Skelettstatus mit zusätzlichem präventivem Nutzen bezüglich muskuloskelettaler Verletzungen dar. Ferner können muskuläre Serummarker, z. B. Laktatdehydrogenase (LDH), Kreatinkinase (CK), Myoglobin und Aspartat-Aminotransferase (ASAT), helfen, eine metabolische Adaptation an das physische Training festzustellen und Aussagen über die muskuläre Arbeitslast und mögliche Schädigungen zu gewinnen. Die Energieverfügbarkeit kann durch eine entsprechende Bilanzierung sowie die laborchemische Bestimmung der Makro- und Mikronährstoffe eingeschätzt und optimiert werden.

Schlussfolgerungen. Die labordiagnostische Untersuchung besitzt in der Betreuung von Athleten eine sportartenübergreifende klinische Relevanz. Sie dient der Erreichung einer höchstmöglichen Leistungsfähigkeit sowie optimalen Prävention von Knochenund Muskelverletzungen, wobei sämtliche Mangelzustände (z. B. Vitamin D) ausgeglichen werden sollten. Durch eine Periodisierung der laborchemischen Untersuchungen, mit zumindest zwei Labordiagnostiken im Jahr, und Aufstellung individueller Variabilitätsund Referenzbereiche kann ferner eine bessere Beurteilbarkeit erreicht werden.

\section{Schlüsselwörter}

Biomarker - Professionelle Athleten . Regeneration · Stressfraktur · Vitamin D

\section{Musculoskeletal laboratory diagnostics in competitive sport}

\section{Abstract}

Background. Laboratory diagnostics represent a valuable tool for the optimization and assessment of the performance and regeneration ability in professional athletes. Blood parameters play an important role in the prevention, diagnosis and rehabilitation of injuries and physical overload.

Objectives. The aim of this article is to present an overview of musculoskeletal laboratory parameters and to provide relevant information for the medical care of competitive athletes.

Methods. Literature search and narrative review.

Results. The laboratory assessment of bone metabolism includes vitamin $\mathrm{D}$, calcium and bone turnover and aims to provide a preventive benefit with respect to skeletal complications (e.g., to minimize the risk of bone stress injuries). In addition, muscular serum markers, such as lactate dehydrogenase (LDH), creatine kinase (CK), myoglobin and aspartate aminotransferase (AST) can be used to monitor metabolic adaptation to physical exercise and to obtain information about the muscular workload and potential damage. The energy availability can be estimated and optimized by appropriate balancing and laboratory determination of macro- and micronutrients.

Conclusions. Laboratory diagnostics have a clinical relevance across different sport disciplines. They are intended to support athletes and medical staff on their way to the highest possible performance and help to ensure the optimal prevention of bone and muscle injuries. Parameters with deficiency results (e.g., vitamin $D$ ) should be adequately compensated. A periodization of the laboratory tests, with at least two tests per year, and the establishment of individual variability and reference ranges can improve the assessment.

\section{Keywords}

Biomarker · Professional athletes - Regeneration $\cdot$ Stress fractures $\cdot$ Vitamin D
Auch was die Rekonvaleszenz nach eingetretener Fraktur anbetrifft, scheint Vitamin D eine entscheidende Rolle zu spielen. In einem Kollektiv von 617 Patienten beider Geschlechter konnte gezeigt werden, dass sich die Inzidenz einer verzögerten Frakturheilung („delayed union") bei Patienten mit VitaminD-Mangel (9,7\%) signifikant von denen mit einem suffizienten VitaminD-Spiegel (0,3\%) unterschied [23]. Bei Patienten mit initialem Mangel und anschließender Supplementation von
1200 IE Vitamin D täglich über 4 Monate konnte eine „delayed union“ ebenfalls signifikant reduziert werden [23]. Dieses verdeutlicht eindrücklich, dass selbst bei einer Vitamin-D-Insuffizienz zum Zeitpunkt einer Fraktur ein Ausgleich dieses Defizits von großem klinischem Nutzen sein kann. Die Bedeutung eines ausgeglichenen Vitamin-D-Spiegels und einer balancierten Calciumhomöostase bezüglich der klinischen und radiologischen Entwicklung von Stressfrakturen bei Leistungssportlern kann im ange- führten Fallbeispiel verdeutlicht werden, in dem bei einer Marathonläuferin nach konsequenter Anpassung der Belastung und einer adäquaten Vitamin-DSupplementation eine Ausheilung der Stressfraktur erreicht werden konnte (• Abb. 2).

Um die Balance des Knochenstoffwechsels beurteilen zu können, werden laborchemische Knochenformationsund Knochenresorptionsmarker herangezogen. Ihre Messwerte spiegeln das Ausmaß des Knochenaufbaus bzw. -ab- 


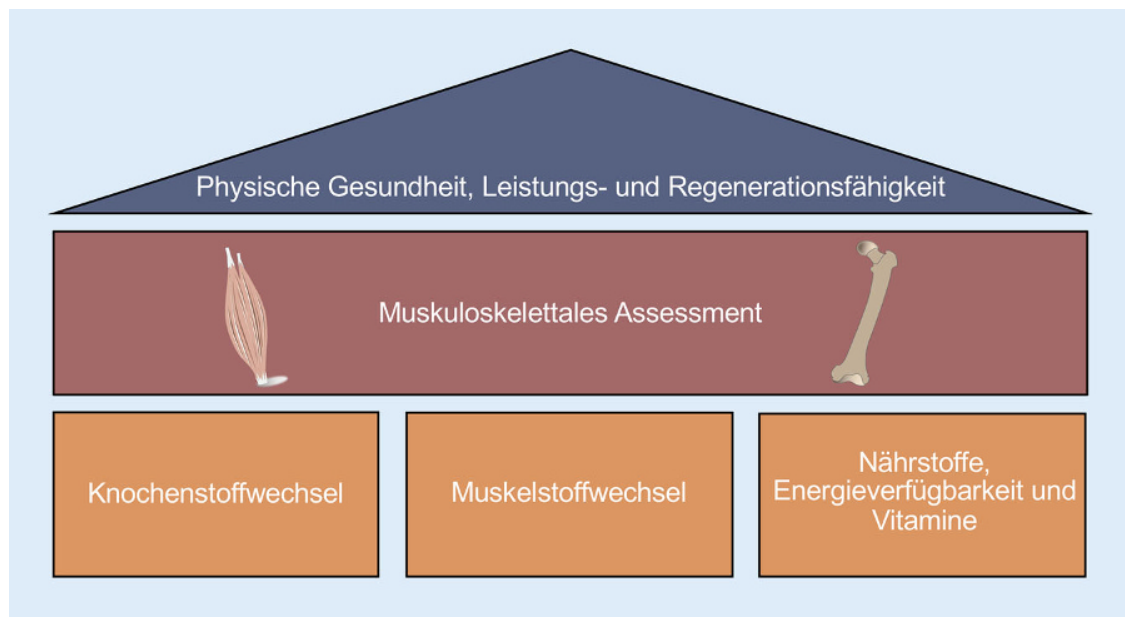

Abb. 1 A Darstellung der Grundsäulen der laborchemischen muskuloskelettalen Diagnostik
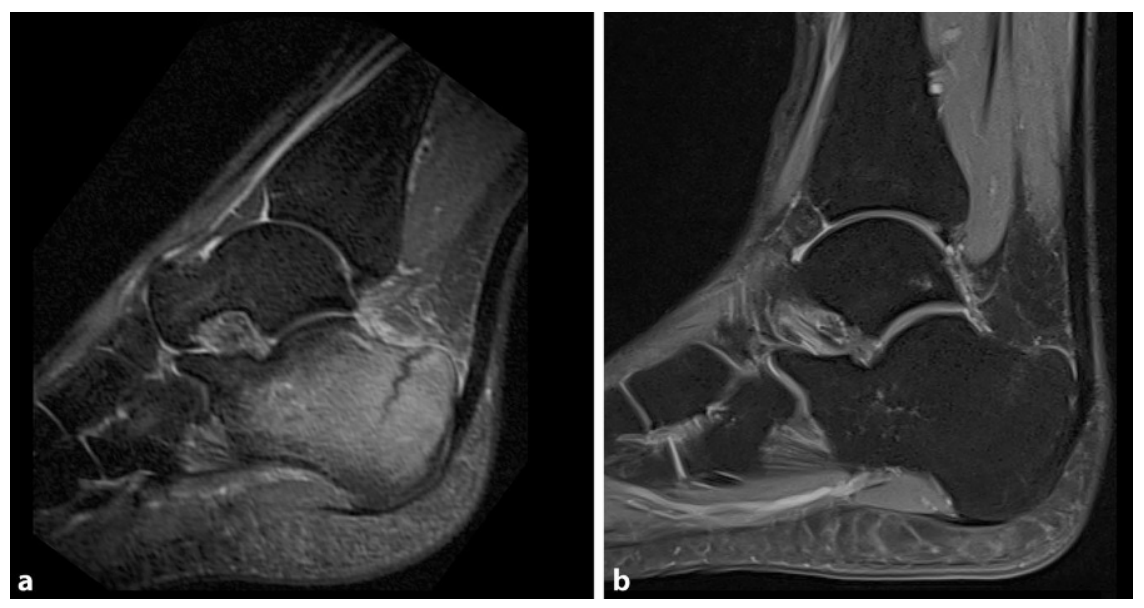

Abb. $2 \Delta$ Magnetresonanztomographie (sagittale, protonengewichtete Sequenz) einer Stressfraktur des rechten Kalkaneus einer 29-jährigen Marathonläuferin. a Stressfraktur des rechten Kalkaneus mit Frakturspalt und ausgeprägtem Knochenmarködem, aufgetreten im Rahmen der Marathontrainingsphase. Die laborchemische Analyse ergab eine Störung der Calcium-Phosphat-Homöostase bei enteraler Calciumaufnahmestörung infolge eines Vitamin-D-Mangels $(19,6 \mathrm{ng} / \mathrm{ml})$ trotz normo-turnover Knochenstoffwechselsituation (Desoxypyridinolin [DPD]: $5 \mathrm{nmol} / \mathrm{mmol}$ ). Ferner fielen ein diskreter Phosphatmangel $(0,82 \mathrm{mmol} / \mathrm{l})$ bei normwertigem Calcium $(2,3 \mathrm{mmol} / \mathrm{l})$ und hochnormalem Parathormon (im Sinne eines funktionellen Hyperparathyreoidismus) bei ansonsten unauffälliger Laboranalyse auf. Nach erfolgreicher Stabilisierung der Calciumhomöostase unter Vitamin-D-Substitution (Vitamin D $>40 \mathrm{ng} / \mathrm{ml}$ ) und Entlastung für 8 Wochen wurde die Läuferin beschwerdefrei und konnte das Training wieder aufnehmen. $\mathbf{b}$ Eine Kontroll-MRT, die ca. 1 Jahr nach Wiederaufnahme des vollen Trainingsumfangs angefertigt wurde, zeigte einen unauffälligen Befund mit Konsolidierung der Fraktur

baus wider. Formationsmarker stellen unter anderem die knochenspezifische alkalische Phosphatase („,bone-specific alkaline phosphatase" $[\mathrm{BAP}])$ und das Osteocalcin (Oc) dar. Die BAP gehört als enzymatisches Isoenzym der ubiquitär vorkommenden Gesamt-AP an. Die Bestimmung der BAP wird der GesamtAP aufgrund der höheren Spezifität vorgezogen. Sie ist an allen Phasen der Knochenmineralisation beteiligt und giestoffwechsels sowie der Fertilität, einnimmt $[26,27]$. Durch das Fehlen einer methodischen Standardisierung und der geringen Halbwertszeit variieren die Werte zum Teil stark zwischen verschiedenen Laboren, was die Aussagekraft einschränken kann [24]. Eine laborchemische Dissoziation zwischen erhöhter beziehungsweise hoch normaler BAP bei Vorliegen eines in Relation deutlich niedrigeren Osteocalcins spricht für das Vorliegen einer osteomalazischen Komponente, das heißt einer Mineralisationsstörung des Knochens. Durch das Auftreten höherer Osteocalcin- und BAP-Werte bei Triathleten im Vergleich zu Radfahrern kann außerdem darauf geschlossen werden, dass sich die individuellen körperlichen Belastungen bei verschiedenen Sportarten bezüglich des Effekts auf den Knochenmetabolismus unterscheiden können [28]. Hier wird davon ausgegangen, dass die auftretenden Maximalkräfte maßgeblich für einen osteogenen Stimulus sind, was sich in erhöhten Knochenformationsmarkern äußert [28, 29].

Ein bewährter Knochenresorptionsmarker, der die Osteoklastenaktivität widerspiegelt, stellt die Kollagenquervernetzung („Crosslink“) Desoxypyridinolin (DPD) dar. DPD fungiert als molekulare Brücke der Extrazellulärmatrix zwischen Kollagenmolekülen des Typs 1 und ist nahezu ausschließlich im Knochen und Dentin anzutreffen. Nach resorptiver Wirkung der Osteoklasten resultiert eine vermehrte Abgabe derCrosslinks an Blut und Urin, wo sie quantitativ bestimmt werden können. Goldstandard ist die Bestimmung der DPD-Konzentration im Urin. Erhöhte DPD-Konzentrationen stehen somit mit einer katabolen Knochenstoffwechsellage und einem erhöhten Risiko für Knochenfrakturen im direkten Zusammenhang und können über die Reduktion der Knochenmineraldichte mit der Entstehung einer Osteoporose assoziiert sein [24, 30]. Generell gilt es zu beachten, dass Jugendliche höhere Formations- und Resorptionsmarker aufgrund des gesteigerten Knochenumbaus während des Wachstums aufweisen [31]. 


\section{Muskelstoffwechsel}

Die Erfassung des Muskelstoffwechsels ist im funktionellen Assessment respektive der Leistungsdiagnostik von Athleten ein wichtiger Bestandteil. Neben direkten Traumata können sich auch intensive körperliche Belastungen bei Ungleichgewicht zwischen Belastung und Trainingsadaptation in Mikro- oder Makroschädigungen in den Muskeln äußern. Mittels Serummarker wie der Laktatdehydrogenase (LDH), der Kreatinkinase (CK), dem Myoglobin und der Aspartat-Aminotransferase $($ ASAT $=$ GOT $)$ lässt sich ein Monitoring der metabolischen Adaptation an das physische Training durchführen und es lassen sich Aussagen über die muskuläre Arbeitslast oder mögliche Schädigungen gewinnen [32]. Die messbaren Enzymaktivitäten zeigen eine direkte Korrelation zu der Belastungsintensität und können bis zu dem 4 fachen des Ausgangswertes ansteigen [32]. Eine medikamenteninduzierte Erhöhung (z.B. CK-Erhöhung bei Statinen oder Steroiden) muss bei der Interpretation mitberücksichtigt werden [33].

Die CK katalysiert die Phosphorylierung von Adenosindiphosphat (ADP) zu Adenosintriphosphat (ATP) und besitzt daher eine zentrale Rolle im Energiestoffwechsel. Isoenzyme sind in verschiedenen Organen vorzufinden: CK-MM im Skelettmuskel, CK-MB im Herzmuskel und CK-BB im Gehirn. Unter physiologischen Umständen ist ausschließlich CKMM im Blutserum nachzuweisen. Das Vorkommen anderer Isoenzyme sollte als verdächtig betrachtet werden. Zwar wurde unter anderem ein Nachweis von CK$\mathrm{MB}$ bei Ultramarathonläufern und CKBB bei Boxern beobachtet [33, 34], allerdings sollten diese Nachweise immer kritisch hinterfragt werden. Ebenfalls sollte bei Vorliegen einer erhöhten GesamtCK-Aktivität in Ruhephasen, auch bei Fehlen von prädisponierenden Faktoren, eine Diagnostik samt kardialer Labordiagnostik und Echokardiografie erfolgen. $\mathrm{Zu}$ beachten ist, dass Sportler physiologisch höhere CK-Aktivitäten besitzen als sportlich inaktive Menschen [33, 35]. So empfahlen Meyer et al. nach Analyse von 467 männlichen Profifußballspielern der 1. und 2. Bundesliga fußballspezifische Referenzbereiche für die CK. Grund für erhöhte CK-Werte scheinen die fußballspezifischen Bewegungen mit ihrem Stop-and-go-Charakter zu sein, welche zu einer hohen exzentrischen Belastung führen und eine stärkere Freisetzung der CK aus dem Zytosol der Muskelzellen bedingen [35]. Da generell bei den meisten Athleten nach körperlichen Belastungen ein Anstieg der CK zu verzeichnen ist, wird sie zum Nachweis von Skelettmuskelschäden bei Sportlern selten verwendet. Nach körperlicher Belastung sind bei einigen Athleten aufgrund der Trainingsadaptation geringere respektive sogar kaum vorhandene Anstiege der CKAktivität $\mathrm{zu}$ verzeichnen, man spricht hier von Non-Respondern [33, 36].

Ein Performance-Test mit maximaler Ausbelastung des Athleten kann für eine Evaluation der Variabilität der individuellen CK-Werte von Nutzen sein. Messungen vor der Belastung und $30 \mathrm{~min}$, $6 \mathrm{~h}, 24 \mathrm{~h}, 48 \mathrm{~h}$, und $72 \mathrm{~h}$ nach der körperlichen Anstrengung scheinen sinnvoll, um den dynamischen Verlauf darzustellen. Ein Peak der CK-Aktivität nach $24 \mathrm{~h}$ ist zu erwarten, während eine Normalisierung nach $48-72 \mathrm{~h}$ folgen sollte [33]. Unterschiede der physischen Belastungscharakteristika zwischen Kraft- und Ausdauerathleten sind bei der Interpretation $\mathrm{zu}$ beachten. So lassen sich bei Kraftathleten, vor allem nach Ausübung von exzentrischem Krafttraining, hohe CKAktivitäten nachweisen [37, 38].

Die LDH, ein Enzym aus der Gruppe der Oxidoreduktasen, wandelt, unter Umwandlung von $\mathrm{NAD}^{+}$und seiner reduzierten Form NADH, Pyruvat und Laktat ineinander um. Nach körperlicher Belastung beziehungsweise muskulären Verletzungen resultieren im Vergleich zur CK langsamer steigende LDHAktivitäten, welche nach ausdauernder körperlicher Aktivität für 14 Tage erhöht sein können [39]. Der Anstieg geschieht vor allem am dritten bis fünften Tag nach dem Reiz [32]. Während sich nicht trainierte Menschen bezüglich der LDHKonzentration in Ruhe nicht von trainierten Athleten unterscheiden, konnte bei diesen bereits nach einem 300-mSprint im Vergleich zu Athleten signifikant höhere LDH-Konzentrationen be- stimmt werden [40]. Dieses lässt eine schnellere Schädigung des Muskelgewebes durch eine fehlende Trainingsadaptation vermuten und unterstreicht die Notwendigkeit eines guten Trainingszustandes, um Muskelverletzungen präventiv entgegenzuwirken.

Das seit vielen Jahren im Breiten- sowie im Spitzensport als diagnostisches Tool zur Leistungsdiagnostik und Trainingssteuerung verwendete Laktat entsteht bei hohen körperlichen Belastungen aus Pyruvat, welches während der anaeroben Glykolyse mithilfe der Laktatdehydrogenase in Laktat umgewandelt wird. Kurz zusammengefasst steigt mit verbessertem Trainingszustand die Laktatkonzentration erst bei einer höheren Belastung an. Somit spiegelt die Laktatkonzentration im Blut die kurzfristige (innerhalb von Minuten) metabolische Beanspruchung wider, wobei das Konzept der Laktatschwellen den Übergang von einer aeroben zur anaeroben Energiebereitstellung umfasst [41]. Die in standardisierten Belastungsprotokollen gemessenen Laktatwerte stellen in Form von Laktatleistungskurven eine seit vielen Jahren genutzte, unverzichtbare Hilfe in der leistungsorientierten Trainingssteuerung dar, obwohl dieses diagnostische Mittel auch einige Schwächen offenbart, wie die Abhängigkeit von anderen Faktoren wie der Ernährung oder der Vorbelastung [42].

Das zytoplasmatische Hämoprotein Myoglobin, welches aus einer Polypeptidkette und einem Porphyrinring mit zentralem Eisenmolekül besteht, stellt das sauerstoffbindende Protein des Muskels dar. Es wird ausschließlich in den Herzmuskelzellen und in oxidativen Skelettmuskelfasern exprimiert und ist fähig, Sauerstoff $\left(\mathrm{O}_{2}\right)$ reversibel zu binden. Es ist in der Lage, bei Vorliegen einer Hypoxie Sauerstoff der Oxidation zur Verfügung zu stellen. Nach anstrengender körperlicher Betätigung kommt es durch den Abbau von Muskelproteinen $\mathrm{zu}$ einer Freisetzung von Myoglobin, welches bereits nach $30 \mathrm{~min}$ messbar ist [43]. Eine erhöhte Myoglobinkonzentration kann für 5 Tage verbleiben, vermutlich aufgrund moderater Inflammationsprozesse [32]. So ist eine Korrelation der Aktivitäten von 
CK und Myoglobin mit der durch Stress induzierten Reaktion der neutrophilen Granulozyten bekannt, wobei eine ausreichende Proteinzufuhr eine Abschwächung des Anstiegs bewirken kann [32]. Im Blut wird es hauptsächlich - neben anderen Parametern - zum Ausschluss eines kardialen Geschehens genutzt. Als weiterer Serummarker für Muskelschädigungen kann die Transaminase ASAT angesehen werden, für welche Meyer und Kollegen ebenfalls einen fußballund mannschaftssportspezifischen Referenzbereich empfehlen [35]. Die ASAT stellt hierbei im Gegensatz zur leberspezifischen Transaminase ALAT (AlaninAminotransferase $=\mathrm{GPT}$ ) eine ubiquitär und in großem Maße in den Muskelzellen vorkommende Transaminase dar.

Neben der Leistungsdiagnostik bietet das laborchemische Assessment mit den daraus abgeleiteten Handlungsempfehlungen weitere Möglichkeiten, die muskuläre Leistungsfähigkeit des Athleten zu optimieren, wie zum Beispiel durch ein Monitoring des Vitamin-D-Spiegels. Ein ausgeglichener Vitamin-D-Haushalt stellt eine wichtige Voraussetzung für die muskuläre Leistungsfähigkeit dar. Bei 61 männlichen britischen Athleten verschiedener Sportarten (Rugby, Fußball und professionelle Pferderennreiter) konnte durch die Optimierung des Vitamin-D-Status bereits nach einer 8-wöchigen Supplementation von 5000 IE Vitamin D pro Tag eine signifikante Verbesserung der 10-m-Sprintzeit und der vertikalen Sprungfähigkeit festgestellt werden [44]. Bei 24 professionellen Balletttänzern und -tänzerinnen, bei denen initial Vitamin-D-Spiegel von $<30 \mathrm{ng} / \mathrm{ml}$ vorlagen, konnte dieses bestätigt werden: Nach einer 4-monatigen Substitution von 2000 IE Vitamin D pro Tag wurde neben einer Verbesserung der Sprungkraft um 7,1\% außerdem eine signifikante Steigerung der isometrischen Kraft des M. quadriceps femoris um 18,7\% beobachtet [20]. So scheint ein Vitamin-D-Serumwert von $>40 \mathrm{ng} / \mathrm{ml}$ die Muskelkraft und -funktion, vor allem bei Athleten mit schnellkraftbetonten Sportarten, signifikant zu verbessern [45]. Außerdem konnte bei Typ-II-Muskelfasern („fast twitch fibres“), welche essenziell für sportliche Höchstleistung und für die Vermeidung von Stürzen sind, bei Vitamin-D-Mangelzuständen Muskelfaseratrophien mit Fettinfiltrationen und Fibrosen beobachtet werden, die nach Supplementierung partiell reversibel waren [22, 46].

Auch ein Zusammenhang zwischen posttraumatischem und altersbedingtem Muskelabbau und Vitamin D wird vermutet [47]. Weitere Untersuchungen konnten zeigen, dass Vitamin D nicht nur bei der muskulären Zelldifferenzierung, sondern auch bei der Zellproliferation bzw. der Proteinbiosynthese im mitochondrialen Metabolismus der Zellen eine wichtige Rolle spielt. Dies ist unter anderen durch eine Erhöhung des oxidativen Stresses und einer Reduktion der Sauerstoffverbrauchsrate in der Skelettmuskulatur bei Vitamin-D-Mangel zu begründen, wobei die molekularen Mechanismen komplex und zum Teil unerforscht sind [48]. Schlussendlich konnte ein systematisches Review positive Auswirkungen von ausgeglichenen Vitamin-D-Spiegeln auf die Muskelkraft demonstrieren, obwohl eine hohe Variabilität bezüglich der Effektstärken besteht [49]. Bezüglich des Zusammenhangs von niedrigen Vitamin-D-Spiegeln und akuten Muskelverletzungen scheint es hingegen deutlich weniger Evidenz zu geben. Eine Auswahl der geeigneten laborchemischen Parameter der muskuloskelettalen Labordiagnostik ist in der - Tab. 1 dargestellt.

\section{Nährstoffe, Energie- verfügbarkeit und Vitamine}

Eine angemessene körperliche Bewegung und Belastung gilt generell als osteoprotektiv. So konnte bei Athletengruppen aus Sportarten mit hohen Maximalkräften und multidirektionalen Bewegungen, wie z.B. Fußball, Volleyball oder auch Rugby, eine bessere Knochenqualität festgestellt werden, während Athleten aus Ausdauersportarten mit niedrigen Maximalkräften und niedriger Energieverfügbarkeit, wie Langstreckenlauf, Schwimmen oder Radrennen, eine reduzierte Knochenmasse aufwiesen [50]. Da $90 \%$ der Gesamtknochenmasse bis zum 20. Lebensjahr generiert werden und der Aufbau mit dem 30. Lebensjahr weitgehend abgeschlossen ist („peak bone mass") [50], ist anzustreben, dass

Hier steht eine Anzeige. 
Tab. 1 Laborchemische Parameter in der muskuloskelettalen Labordiagnostikund Bedeutung für den Athleten sowie Interpretation von Abweichungen

\begin{tabular}{|c|c|c|}
\hline Parameter & Bedeutung & Abweichung \\
\hline Calcium $^{\mathrm{a}}$ & $\begin{array}{l}\text { Mineralstoff der Skelettminerali- } \\
\text { sation }\end{array}$ & $\begin{array}{l}\downarrow \text { Höhere Inzidenz für Stressfrakturen [16]; chronischer Mangel kann in einer Osteomalazie } \\
\text { resultieren }\end{array}$ \\
\hline Phosphat $^{\mathrm{a}}$ & $\begin{array}{l}\text { Mineralstoff der Skelettminerali- } \\
\text { sation }\end{array}$ & $\downarrow$ Chronischer Mangel kann in einer hypophosphatämischen Osteomalazie resultieren [6] \\
\hline $\begin{array}{l}\text { Vitamin D } \\
\left(25(\mathrm{OH}) \mathrm{D}_{3}\right)^{\mathrm{a}}\end{array}$ & $\begin{array}{l}\text { Schlüsselfunktion in der Calcium- } \\
\text { homöostase und Skelettminerali- } \\
\text { sation }\end{array}$ & 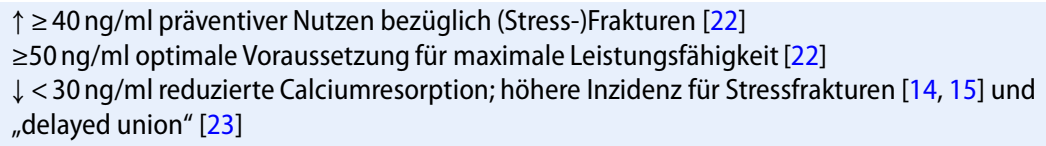 \\
\hline Osteocalcin (Oc) ${ }^{\mathrm{a}}$ & $\begin{array}{l}\text { Calciumbindendes Peptidhormon } \\
\text { der Osteoblasten; Knochenforma- } \\
\text { tionsmarker }\end{array}$ & $\downarrow$ Kataboler/„low-turnover“ Knochenstoffwechsel $[24,28]$ \\
\hline $\begin{array}{l}\text { Knochenspezifische } \\
\text { AP (BAP) }\end{array}$ & $\begin{array}{l}\text { Enzym der Knochenformation; } \\
\text { Knochenformationsmarker }\end{array}$ & $\begin{array}{l}\uparrow \text { Bei Dissoziation zu Osteocalcin (Verhältnis BAP>Oc): Hinweis auf osteomalazische Kom- } \\
\text { ponente } \\
\downarrow \text { Kataboler/„low-turnover“ Knochenstoffwechsel [24], Hypophosphatasie }\end{array}$ \\
\hline $\begin{array}{l}\text { Desoxypyridinolin } \\
(\mathrm{DPD})^{\mathrm{a}}\end{array}$ & $\begin{array}{l}\text { Produkt der Knochenresorption; } \\
\text { Knochenresorptionsmarker }\end{array}$ & $\uparrow$ Erhöhte Knochenresorption mit gesteigertem Risiko für Frakturen [24] \\
\hline Parathormon (PTH) ${ }^{\mathrm{a}}$ & $\begin{array}{l}\text { Regulationsfunktion in der Calci- } \\
\text { umhomöostase }\end{array}$ & $\begin{array}{l}\uparrow \text { Primärer/tertiärer Hyperparathyreoidismus: Calcium ( } \uparrow) \text {, Phosphat }(\downarrow) \text {; sekundärer Hyper- } \\
\text { parathyreoidismus: Calcium }(\downarrow / n) \text {, Phosphat }(\uparrow / n)[9,12]\end{array}$ \\
\hline Kreatinkinase $(\mathrm{CK})^{\mathrm{b}}$ & $\begin{array}{l}\text { Energiebereitstellung durch Re- } \\
\text { phosphorylierung von ADP zu ATP }\end{array}$ & $\begin{array}{l}\uparrow \text { Muskelzellschädigung; medikamenteninduziert (beispielsweise Statine, Steroide) [33]; } \\
\text { potenzielles Übertraining [76] }\end{array}$ \\
\hline $\begin{array}{l}\text { Laktatdehydrogenase } \\
(\mathrm{LDH})^{\mathrm{b}}\end{array}$ & $\begin{array}{l}\text { Energiebereitstellung im anaero- } \\
\text { ben Energiestoffwechsel }\end{array}$ & $\uparrow$ Muskelzellschädigung [39] \\
\hline $\begin{array}{l}\text { Aspartat-Aminotrans- } \\
\text { ferase }(\text { ASAT) }\end{array}$ & $\begin{array}{l}\text { Transaminase mit ubiquitärem } \\
\text { Vorkommen }\end{array}$ & $\uparrow$ Muskel- und Leberzellschädigung durch körperliche Belastung [77] \\
\hline Laktat $^{\mathrm{b}}$ & $\begin{array}{l}\text { Endprodukt der anaeroben Glyko- } \\
\text { lyse }\end{array}$ & $\uparrow$ Akute körperliche Belastung; potenzielles Übertraining [76] \\
\hline Magnesium (Mg) & $\begin{array}{l}\text { Mineralstoff mit Einfluss auf die } \\
\text { Skelettmineralisation }\end{array}$ & $\begin{array}{l}\uparrow \text { Aktivierung der Osteoklasten [67] } \\
\downarrow \text { Inhibierung der Osteoblasten und Aktivierung der Osteoklasten [67]; Verringerung der } \\
\text { muskulären Leistungsfähigkeit und Integrität [68] }\end{array}$ \\
\hline Eisen, Ferritin (Fe) & $\begin{array}{l}\text { Mineralstoff mit Einfluss auf die } \\
\text { Blutbildung und Leistungsfähig- } \\
\text { keit }\end{array}$ & $\begin{array}{l}\downarrow \text { Erhöhtes Risiko für Frakturen und verlängerte Regenerationsdauer nach Verletzungen [50, } \\
61]\end{array}$ \\
\hline Zink (Zn) & $\begin{array}{l}\text { Mineralstoff mit Einfluss auf die } \\
\text { Skelettmineralisation }\end{array}$ & $\begin{array}{l}\downarrow \text { Negativer Effekt auf die Skelettmineralisation mit möglichem reduziertem Knochenmine- } \\
\text { ralsalzgehalt [70] }\end{array}$ \\
\hline
\end{tabular}

trotz einer aktiven Sportlerkarriere in diesen Jahren suffiziente Bedingungen für einen Knochenmasseaufbau geboten werden. Als positiver Stimulus für den Knochenstoffwechsel wird der mechanischen Belastung der Knochen mit dem Auftreten von Maximalkräften eine entscheidende Rolle beigemessen [51]. Dabei stellt jedoch ein weiterer wichtiger Einflussfaktor die Ernährung respektive die Energieverfügbarkeit dar.

Ihle und Loucks (2004) untersuchten die Dosis-Wirkungs-Beziehung zwischen drei Stufen verminderter Energieverfügbarkeit und dem Knochenstoffwechsel von jungen gesunden Frauen im Vergleich zu energiebalancierten Kon- trollen mit einer Energieverfügbarkeit von $45 \mathrm{kcal} / \mathrm{kg}$ fettfreier Körpermasse („lean body mass“ [LBM])/Tag. So waren bei Energieverfügbarkeiten von 30 beziehungsweise $20 \mathrm{kcal} / \mathrm{kg} \mathrm{LBM} / \mathrm{Tag}$ signifikant geringere Knochenformationsraten zu detektieren, während die Knochenresorption noch unverändert blieb. Bei weiterer Reduktion der Energieverfügbarkeit auf $10 \mathrm{kcal} / \mathrm{kg} \mathrm{LBM} / \mathrm{Tag}$ stieg zusätzlich die Knochenresorption an, mit der Gefahr einer katabolen Knochenstoffwechsellage [52]. Hier gilt es $\mathrm{zu}$ beachten, dass neben einer geringeren Energieaufnahme auch ein hoher Energieverbrauch bei Athleten eine geringere Energiebilanz bedingt, was vor allem für Ausdauerathleten relevant ist. So werden Eliteausdauerathleten das Niveau von $45 \mathrm{kcal} / \mathrm{kg}$ LBM/Tag angesichts der hohen Energieausgaben nur schwerlich erreichen können [53]. AuBerdem sehen viele Ausdauersportler ein Energiedefizit als essenziell an, um den Phänotyp des Ausdauerathleten mit einem möglichst großen Anteil fettfreier Masse zu generieren. Nichtsdestotrotz ist eine ausreichende Energieverfügbarkeit beziehungsweise suffiziente Versorgung mit Nährstoffen anzustreben, um die kurz- und langfristige Knochengesundheit zu gewährleisten.

Die Kombination aus einer geringen Energieverfügbarkeit (mit oder ohne Ess- 


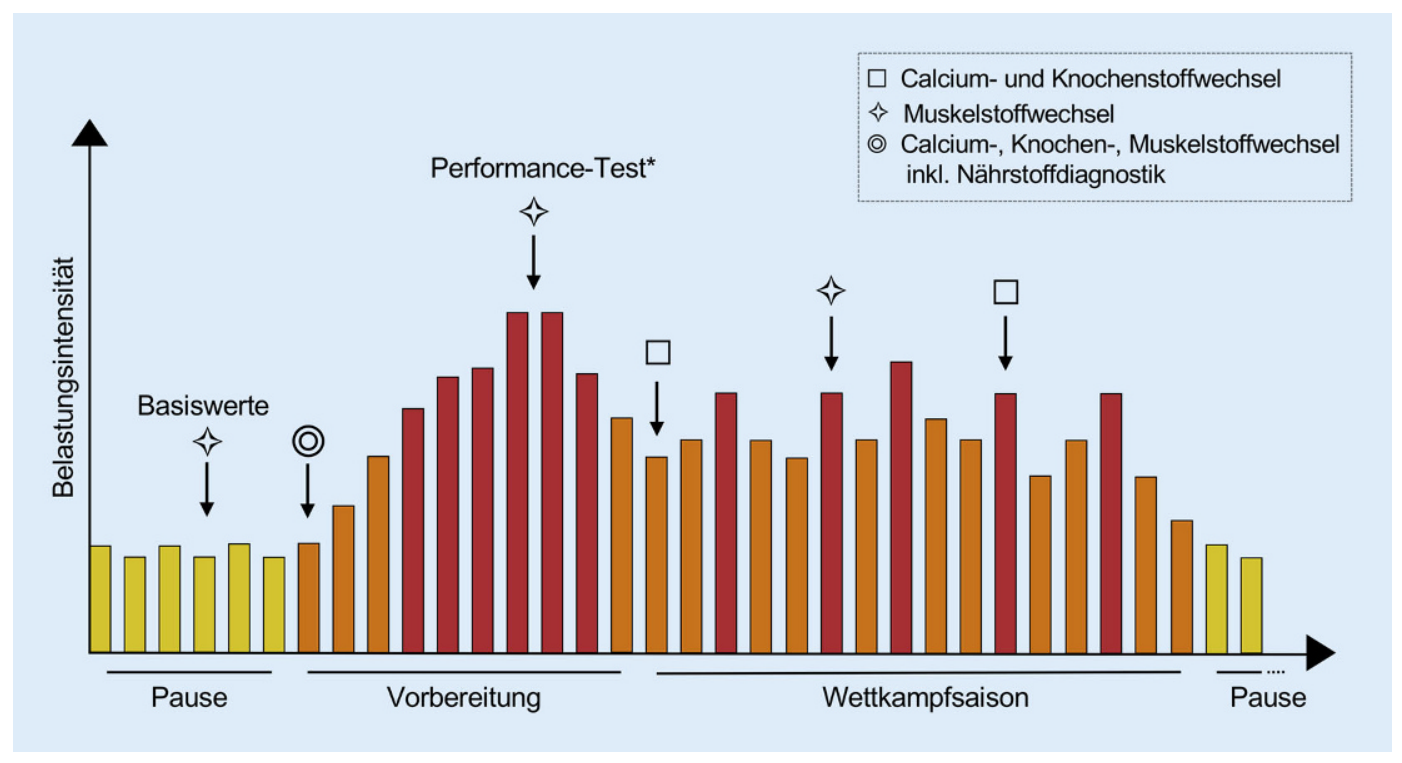

Abb. 3 ॥ Schematische Darstellung einer Periodisierung der labordiagnostischen Untersuchungen unter Berücksichtigung eines Saisonverlaufs. Umfassende Laborkontrollen (Ring) des Calcium-, Knochen- und Muskelstoffwechsels inklusive einer Nährstoffdiagnostik gemäß der Parameter aus —Tab. 1 sind zu Beginn der Vorbereitungsphase zu empfehlen. Laboranalysen außerhalb der Wettkampfsaison liefern individuelle und basale Referenzwerte der Muskelenzyme (Stern). Analysen während der gesteigerten körperlichen Belastung, wie der Vorbereitungszeit, zeigen die individuelle Variabilität dieses Referenzbereichs auf und dienen der Leistungsdiagnostik. Eine Laboruntersuchung vor und nach einer hochintensiven Trainingseinheit, im Sinne eines Performance-Tests, kann individuelle Peaks der belastungsabhängigen Muskelenzyme aufzeigen. Im Rahmen dessen ist eine leistungsphysiologische Untersuchung, z. B. eine Laktatdiagnostik oder Spiroergometrie, anzuraten $\left({ }^{*}\right)$. Während der laufenden Wettkampfsaison kann auf Basis der zuvor erhobenen Werte ein Monitoring durchgeführt werden. Kontrollen des Calcium- und Knochenstoffwechsels (Quadrat) sind in regelmäßigen Abständen (z. B. alle 2-3 Monate je nach Belastungsgrad) sinnvoll. Es muss berücksichtigt werden, dass die Empfehlung der abzunehmenden Werte stark von der Sportart, dem Belastungsniveau und Anspruch sowie der Länge einer Saison abhängig gemacht werden sollte. Für die genaue Interpretation der einzelnen Parameter siehe $\bullet$ Tab. 1

störung), einem veränderten Menstruationszyklus mit niedrigeren Östrogenen und anderen Hormonstörungen und einer verminderten Knochenmineraldichte („bone mineral density“ [BMD]) beschreibt einen Zustand, der vor allem bei intensiv sporttreibenden Frauen beobachtet wird und vormals als „female athlete triad" bezeichnet wurde [54]. Da mittlerweile bekannt ist, dass der relative Energiemangel die Grundproblematik darstellt und auch Männer betroffen sein können, wurde die Terminologie in „relative energy deficiency in sport" (REDS) geändert [55]. Der Begriff stellt eine Erweiterung der Triade der weiblichen Athletin dar, scheint jedoch im Bewusstsein der Ärztinnen und Ärzte noch nicht ausreichend vertreten zu sein [56]. Neben der langfristigen Verringerung der Knochenmineraldichte wurde in diesem $\mathrm{Zu}$ sammenhang auch eine höhere Inzidenz von Stressfrakturen beschrieben [57].

Als Orientierung für entsprechende Mangelzustände kann neben einer Bilan- zierung der Energieverfügbarkeit eine labordiagnostische Bestimmung von Nährstoffen dienen, um eine Limitation der Entwicklung und Funktionstüchtigkeit des muskuloskelettalen Systems durch das Vorliegen von Mangelzuständen auszuschließen. Das Erkennen und Beseitigen von Mangelzuständen stellt eine Grundvoraussetzung für die Optimierung der Leistungs- und Regenerationsfähigkeit der Athleten dar. Calcium, Vitamin D und Phosphat wurden als maßgebliche osteologische Parameter bereits angeführt. Weitere Parameter stellen als Makronährstoffe die Proteine und als Mikronährstoffe Eisen, Magnesium und Zink sowie Vitamin $\mathrm{B}_{6}, \mathrm{~B}_{9}$ und $\mathrm{B}_{12}$ dar. Die von der International Society of Sports Nutrition (ISSN) empfohlene tägliche Proteinzufuhr für gesunde Sportler liegt bei 1,4-2,0 g Protein/kg Körpergewicht, um durch eine positive Proteinbilanz bestmöglich den Muskelaufbau/-erhalt und die Trainingsadaptation zu garantieren, während einem Muskelverlust vorgebeugt werden soll [58]. Proteine als Bestandteil des Kollagens und der Wachstumsfaktoren haben folglich ebenfalls einen positiven Effekt auf den Knochen [50]. Für eine Beurteilung der individuell benötigten Menge an Proteinen pro Tag können unterstützend Biomarker herangezogen werden (Gesamtprotein, Albumin, Stickstoffbilanz, HarnstoffStickstoff, Aminosäurenanalyse). Eine Fehlernährung mit resultierendem Proteinmangel scheint hierbei mit einer Reduktion der Albuminsynthese und einem verminderten Gesamtprotein einherzugehen. Zusätzlich kann die Stickstoffbilanz, zum Beispiel durch eine Messung des Harnstoff-Stickstoffs als Abbauprodukt von Proteinen (im Blut oder Urin) Aufschlüsse über den Eiweißstoffwechsel liefern und beispielsweise auf Mangelernährung hinweisen [59].

Ein Eisenmangel stellt einen leistungslimitierenden Faktor dar, der sich laborchemisch in Form eines erniedrig- 
ten Ferritins beziehungsweise Hämoglobins im Falle einer Eisenmangelanämie widerspiegelt [60] und sich klinisch unter anderem durch eine Ermüdung (,Fatigue") mit verringerter maximaler Sauerstoffaufnahme $\left(\mathrm{VO}_{2 \max }\right)$ und Dyspnoe äußert [61]. Auf muskuloskelettaler Ebene kann sich ein Eisenmangel in einem erhöhten Risiko für eine herabgesetzte Knochendichte, für Stressfrakturen, oder aber auch durch eine verlängerte Regenerationsdauer nach Verletzungen manifestieren [50, 61-63]. Bei 1085 Eliteathleten ( 570 weiblich, 515 männlich) aus über 26 Sportarten konnte bei $15 \%$ der männlichen und $52 \%$ der weiblichen Athleten ein defizitärer Eisenstatus festgestellt werden [64]. Als möglicher Einflussfaktor der deutlich höheren Prävalenz eines Eisenmangels bei Athletinnen ist hier ein menstruationsbedingter Eisenverlust zu bedenken [65].

Magnesium ( $\mathrm{Mg}$ ) beeinflusst als Cofaktor zahlreicher anaboler und kataboler Reaktionen ebenfalls die Knochengesundheit und Muskelleistung des Athleten [66], wobei niedrige Magnesiumkonzentrationen möglicherweise eine katabole Stoffwechselsituation des Knochens herbeiführen können [67]. Ein positiver Zusammenhang zwischen Magnesiumstatus, der Muskelkraft und der Muskelleistung durch eine muskelprotektive Wirkung respektive Aufrechterhaltung der Muskelintegrität ist ebenfalls bekannt [68]. So konnten bei Radsportlern nach Magnesiumsupplementation $(400 \mathrm{mg} / \mathrm{d})$ während eines 21-tägigen Etappenrennens signifikant niedrigere Myoglobinkonzentrationen nachgewiesen werden [69]. Zink ( $\mathrm{Zn})$ ist ein weiterer Mineralstoff, der aufgrund des erhöhten Bedarfs bei Sportlern abgedeckt sein sollte und für eine Vielzahl von Funktionen der Wundheilung, der Glukoseverwertung und der Proteinsynthese erforderlich ist und sowohl antioxidativ als auch antiinflammatorisch wirkt [59]. Daneben nimmt Zink als Cofaktor mehrerer Enzyme, wie der AP und der Kollagenase, eine Rolle in der Knochenmineralisation und der Synthese der kollagenen Strukturen des Knochens ein [70]. Ein Zinkmangel ist kein seltenes Ereignis und kann durch eine suboptimale Zinkaufnahme bei körperlichen Belastungen, Stress und einseitigen Ernährungsgewohnheiten bedingt sein und zu einer verminderten Knochendichte führen [70, 71].

Vitamine stellen eine Gruppe von lebensnotwendigen organischen Verbindungen unterschiedlicher Stoffklassen dar, welche vom Körper nicht selbst synthetisiert werden können und durch die Nahrung aufgenommen werden müssen. Trotz der Wichtigkeit einer adäquaten Aufnahme der Vitamine C, E und $\mathrm{K}$ ist die Verlässlichkeit und der Nutzen ihrer laborchemischen Bestimmung nicht vollständig nachgewiesen und wird in dieser Arbeit nicht thematisiert. Für das labordiagnostische Assessment sind vor allem die Vitamine $B_{6}, B_{9}$ und $B_{12}$ geeignet. Der Vitamin-B-Komplex spielt eine bedeutende Rolle in der Regulation des Energiemetabolismus [59]. Wichtige Vertreter stellen das $B_{6}$ (Pyridoxin), $B_{9}$ (Folsäure) und $\mathrm{B}_{12}$ (Cobalamin) dar. So hat Pyridoxin eine zentrale Stellung als Coenzym vieler Reaktionen des Aminosäurenstoffwechsels und trägt zur Synthese von Fettsäuren bei [72]. Folsäure ist maßgeblich an Wachstumsund Zellteilungsprozessen im menschlichen Körper beteiligt [73]. Eine Analyse des Cobalamins, welches vorwiegend in tierischen Produkten vorkommt, ist vor allem Vegetariern und Veganern empfohlen und es sollte gegebenenfalls substituiert werden. Ein Cobalaminmangel scheint mit einer Verminderung der Knochendichte sowie einer Beeinträchtigung der Osteoblastenfunktion einherzugehen $[74,75]$.

\section{Periodisierung des labor- chemischen Assessments}

Ein individuelles Vorgehen im Rahmen der Labordiagnostik erscheint sinnvoll, da individuell zwischen Athleten bedeutende Unterschiede der labordiagnostischen Referenzintervalle auftreten. So sind bedeutende belastungsabhängige und sportartspezifische Unterschiede zahlreicher Laborparameter zwischen Athleten nachzuweisen [35, 59]. Es ist sinnvoll, aber zeitlich und technisch aufwändig, durch eine Periodisierung der Messungen personalisierte Referenzund Variabilitätsbereiche der Athleten zu bestimmen, welche im Rahmen von unterschiedlichen Trainings- und Belastungszuständen durchgeführt werden (๑ Abb.3). Es wird jedoch auch deutlich, dass keine pauschale Aussage über die Zeitintervalle zwischen den Laboranalysen sinnvoll ist, sondern ein bedarfsund saisonabhängiges Vorgehen gewählt werden sollte. Ein Mindestmaß von zwei Labordiagnostiken pro Jahr ist jedoch zu empfehlen, um die medizinische Grundversorgung eines Leistungssportlers gewährleisten zu können.

Auch während der Rehabilitation nach einer Verletzung können zuvor erhobene Basiswerte der individuellen Referenz- und Variabilitätsbereiche helfen, Verlaufswerte besser einzuschätzen.

\section{Fazit für die Praxis}

- Ein regelmäßig durchgeführtes labordiagnostisches Assessment (im Leistungssport zumindest zweimal pro Jahr) und die daraus abgeleitete Intervention bei auffälligen Werten kann helfen, die Leistungsfähigkeit von Athleten zu verbessern.

- Eine ausgeglichene Calciumhomöostase sollte durch eine optimale Vitamin-D-Versorgung sowie eine ausgewogene Ernährung angestrebt werden, um das Risiko von Verletzungen wie Stressfrakturen zu verringern.

- Das laborchemische Assessment beinhaltet verschiedene Muskelenzyme, sowie Makro- und Mikronährstoffe unter Berücksichtigung des individuellen Energiebedarfs.

- Allgemeine Referenzbereiche dienen als Orientierung, wobei bei Leistungssportlern ein individuelles Vorgehen mit Aufstellung individueller und ggf. sportartspezifischer Referenzbereiche sinnvoll erscheint.

- Eine detaillierte laborchemische Diagnostik sollte heutzutage fester Bestandteil in der ärztlichen Betreuung von professionellen Athleten. 
Hier steht eine Anzeige.

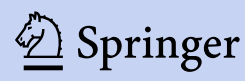




\section{Korrespondenzadresse}

\section{Tim Rolvien}

Fachbereich Orthopädie, Klinik und Poliklinik

für Unfallchirurgie und Orthopädie, Universitätsklinikum Hamburg-Eppendorf Martinistraße 52, 20246 Hamburg, Deutschland t.rolvien@uke.de

Funding. Open Access funding enabled and organized by Projekt DEAL.

\section{Einhaltung ethischer Richtlinien}

Interessenkonflikt. M.M. Delsmann, J. Stürznickel, M. Amling, P. Ueblacker und T. Rolvien geben an, dass kein Interessenkonflikt besteht.

Für diesen Beitrag wurden von den Autoren keine Studien an Menschen oder Tieren durchgeführt. Für die aufgeführten Studien gelten die jeweils dort angegebenen ethischen Richtlinien.

Open Access. Dieser Artikel wird unter der Creative Commons Namensnennung 4.0 International Lizenz veröffentlicht, welche die Nutzung, Vervielfältigung, Bearbeitung, Verbreitung und Wiedergabe in jeglichem Medium und Format erlaubt, sofern Sie den/die ursprünglichen Autor(en) und die Quelle ordnungsgemäß nennen, einen Link zur Creative Commons Lizenz beifügen und angeben, ob Änderungen vorgenommen wurden.

Die in diesem Artikel enthaltenen Bilder und sonstiges Drittmaterial unterliegen ebenfalls der genannten Creative Commons Lizenz, sofern sich aus der Abbildungslegende nichts anderes ergibt. Sofern das betreffende Material nicht unter der genannten Creative Commons Lizenz steht und die betreffende Handlung nicht nach gesetzlichen Vorschriften erlaubt ist, ist für die oben aufgeführten Weiterverwendungen des $\mathrm{Ma}$ terials die Einwilligung des jeweiligen Rechteinhabers einzuholen.

Weitere Details zur Lizenz entnehmen Sie bitte der Lizenzinformation auf http://creativecommons.org/ licenses/by/4.0/deed.de.

\section{Literatur}

1. Darche JP, Murray MJ, Bridges KM, Noland J, Greiner KA (2019) Assessing the utility of yearly pre-season laboratory screening for athletes on a major professional sports team. J Sci Med Sport 22(4):484-487

2. Cook JL, Purdam CR (2009) Is tendon pathology a continuum? A pathology model to explain the clinical presentation of load-induced tendinopathy. Br J Sports Med 43(6):409-416

3. Zaidi M (2007) Skeletal remodeling in health and disease. NatMed 13(7):791-801

4. Cormick G, Belizan JM (2019) Calcium intake and health. Nutrients 11(7):1606

5. Ksiazek A, Zagrodna A, Slowinska-Lisowska M (2020) Assessment of the dietary intake of highrank professional male football players during a preseason training week. Int J Environ Res Public Health 17(22):8567
6. Imel EA, Econs MJ (2012) Approach to the hypophosphatemic patient. J Clin Endocrinol Metab 97(3):696-706

7. Priemel M, von Domarus C, Klatte TO, Kessler $S$, Schlie J, Meier S, Proksch N, Pastor F, Netter C, Streichert T, Puschel K, Amling M (2010) Bone mineralization defects and vitamin $D$ deficiency: histomorphometric analysis of iliac crest bone biopsies and circulating 25-hydroxyvitamin $D$ in 675 patients. J Bone Miner Res 25(2):305-312

8. Shimada T, Hasegawa H, Yamazaki Y, Muto T, Hino R, Takeuchi Y, Fujita T, Nakahara K, Fukumoto S, Yamashita T (2004) FGF-23 is a potent regulator of vitamin $D$ metabolism and phosphate homeostasis. JBone Miner Res 19(3):429-435

9. Silva BC, Cusano NE, Bilezikian JP (2018) Primary hyperparathyroidism. Best Pract Res Clin Endocrinol Metab 32(5):593-607

10. Shimada T, Kakitani M, Yamazaki Y, Hasegawa $H_{\text {, }}$ Takeuchi Y, Fujita T, Fukumoto S, Tomizuka K, Yamashita T (2004) Targeted ablation of Fgf23 demonstrates an essential physiological role of FGF23 in phosphate and vitamin D metabolism. JClin Invest 113(4):561-568

11. Butscheidt $S$, Rolvien $T$, Ueblacker $P$, Amling $M$, Barvencik F (2017) Impact of vitamin D in sports: does vitamin D insufficiency compromise athletic performance? Sportverletz Sportschaden 31(1):37-44

12. Cunningham J, Locatelli F, Rodriguez M (2011) Secondary hyperparathyroidism: pathogenesis, disease progression, and therapeutic options. Clin J Am Soc Nephrol 6(4):913-921

13. Keller J, Schinke T (2013) The role of the gastrointestinal tract in calcium homeostasis and bone remodeling. Osteoporos Int 24(11):2737-2748

14. Williams K, Askew C, Mazoue C, Guy J, TorresMcGehee TM, Jackson IJB (2020) Vitamin D3 supplementation and stress fractures in high-risk collegiate athletes-a pilot study. Orthop Res Rev 12:9-17

15. Miller JR, Dunn KW, Ciliberti LJ Jr., Patel RD, Swanson BA (2016) Association of vitamin D with stress fractures: a retrospective cohort study. J Foot Ankle Surg 55(1):117-120

16. Lappe J, Cullen D, Haynatzki G, Recker R, Ahlf R, Thompson K (2008) Calcium and vitamin d supplementation decreases incidence of stress fractures in female navy recruits. J Bone Miner Res 23(5):741-749

17. Morton JP, lqbal Z, Drust B, Burgess D, Close GL, Brukner PD (2012) Seasonal variation in vitamin D status in professional soccer players of the English Premier League. Appl Physiol Nutr Metab 37(4):798-802

18. Bauer P, Henni S, Dorr O, Bauer T, Hamm CW, Most A (2019) High prevalence of vitamin D insufficiency in professional handball athletes. Phys Sportsmed 47(1):71-77

19. Maroon JC, Mathyssek CM, Bost JW, Amos A, Winkelman R, Yates AP, Duca MA, Norwig JA (2015) Vitamin $D$ profile in National Football League players. Am J Sports Med 43(5):1241-1245

20. Wyon MA, Koutedakis $Y$, Wolman R, Nevill AM, Allen N (2014) The influence of winter vitamin D supplementation on muscle function and injury occurrence in elite ballet dancers: a controlled study. J Sci Med Sport 17(1):8-12

21. Pilz S, Marz W, Cashman KD, Kiely ME, Whiting SJ, Holick MF, Grant WB, Pludowski P, Hiligsmann M, Trummer C, Schwetz V, Lerchbaum E, Pandis $M$, Tomaschitz A, Grubler MR, Gaksch M, Verheyen N, Hollis BW, Rejnmark L, Karras SN, Hahn A, BischoffFerrari HA, Reichrath J, Jorde R, Elmadfa I, Vieth R,
Scragg R, Calvo MS, van Schoor NM, Bouillon R, Lips P, Itkonen ST, Martineau AR, LambergAllardt C, Zittermann A (2018) Rationale and plan for vitamin D food fortification: a review and guidance paper. Front Endocrinol 9:373

22. Shuler FD, Wingate MK, Moore GH, Giangarra $C$ (2012) Sports health benefits of vitamin d. Sports Health 4(6):496-501

23. Gorter EA, Krijnen P, Schipper IB (2017) Vitamin D status and adult fracture healing. J Clin Orthop Trauma 8(1):34-37

24. Banfi G, Lombardi G, Colombini A, Lippi G (2010) Bone metabolism markers in sports medicine. Sports Med 40(8):697-714

25. Zoch ML, Clemens TL, Riddle RC (2016) New insights into the biology of osteocalcin. Bone 82:42-49

26. Lee NK, Sowa $H$, Hinoi $E$, Ferron $M, A h n J D$, Confavreux C, Dacquin R, Mee PJ, McKee MD, Jung DY, Zhang Z, Kim JK, Mauvais-Jarvis F, Ducy P, Karsenty G (2007) Endocrine regulation of energy metabolism by the skeleton. Cell 130(3):456-469

27. Oury F, Sumara G, Sumara O, Ferron $M$, Chang $H$, Smith CE, Hermo L, Suarez S, Roth BL, Ducy P, Karsenty $G$ (2011) Endocrine regulation of male fertility by the skeleton. Cell 144(5):796-809

28. Maimoun L, Mariano-GoulartD, Couret I, Manetta J, Peruchon E, Micallef JP, Verdier R, Rossi M, Leroux JL (2004) Rationale and plan for vitamin D food fortification: a review and guidance paper.J Sports Sci 22(9):875-883

29. Creighton DL, Morgan AL, Boardley D, Brolinson PG (1985) Weight-bearing exercise and markers of bone turnover in female athletes. J Appl Physiol 90(2):565-570

30. Park SG, Jeong SU, Lee JH, Ryu SH, Jeong HJ, Sim YJ, Kim DK, Kim GC (2018) The changes of CTX, DPD, osteocalcin, and bone mineral density during the postmenopausal period. Ann Rehabil Med 42(3):441-448

31. Bayer M (2014) Reference values of osteocalcin and procollagen type IN-propeptide plasma levels in a healthy Central European population aged 0-18 years. Osteoporos Int 25(2):729-736

32. Brancaccio P, Lippi G, Maffulli N (2010) Biochemical markers of muscular damage. Clin Chem Lab Med 48(6):757-767

33. Brancaccio P, Limongelli FM, Maffulli N (2006) Monitoring of serum enzymes in sport. Br J Sports Med 40(2):96-97

34. Kilianski J, Peeters S, Debad J, Mohmed J, Wolf SE, Minei JP, Diaz-Arrastia R, Gatson JW (2017) Plasma creatine kinase $B$ correlates with injury severity and symptoms in professional boxers. J Clin Neurosci 45:100-104

35. Meyer T, Meister S (2011) Routine blood parameters in elite soccer players. Int J Sports Med 32(11):875-881

36. Urhausen A, Kindermann W (2000) Aktuelle Marker für die Diagnostik von Überlastungszuständen in der Trainingspraxis. Dtsch ZSportmed 51(7):8

37. Brancaccio P, Maffulli N, Limongelli FM (2007) Creatine kinase monitoring in sport medicine. $\mathrm{Br}$ Med Bull 81-82:209-230

38. Kim J, Lee J (2015) The relationship of creatine kinase variability with body composition and muscle damage markers following eccentric muscle contractions. J Exerc Nutrition Biochem 19(2):123-129

39. Brancaccio P, Maffulli N, Buonauro R, Limongelli FM (2008) Serum enzyme monitoring in sports medicine. Clin Sports Med 27(1):1-18, vii.

40. Klapcinska B, Iskra J, Poprzecki S, Grzesiok K (2001) The effects of sprint $(300 \mathrm{~m})$ running on 
plasma lactate, uric acid, creatine kinase and lactate dehydrogenase in competitive hurdlers and untrained men. J Sports Med Phys Fitness 41(3):306-311

41. Billat LV (1996) Use of blood lactate measurements for prediction of exercise performance and for control of training. Recommendations for longdistance running. Sports Med 22(3):157-175

42. Heck H, Beneke R (2008) 30 Jahre Laktatschwellen-was bleibt zu tun? Dtsch Z Sportmed 59(12):297

43. Ascensao A, Rebelo A, Oliveira E, Marques F, Pereira L, Magalhaes J (2008) Biochemical impact of a soccer match-analysis of oxidative stress and muscle damage markers throughout recovery. Clin Biochem 41(10-11):841-851

44. Close GL, Russell J, Cobley JN, Owens DJ, Wilson G, Gregson W, Fraser WD, Morton JP (2013) Assessment of vitamin D concentration in non-supplemented professional athletes and healthy adults during the winter months in the UK: implications for skeletal muscle function. J Sport Sci31(4):344-353

45. Zhang L, Quan M, Cao ZB (2019) Effect of vitamin D supplementation on upper and lower limb muscle strength and muscle power in athletes: A metaanalysis. PLoSONE 14(4):e215826

46. Oh JH, Kim SH, Kim JH, Shin YH, Yoon JP, Oh CH (2009) The level of vitamin D in the serum correlates with fatty degeneration of the muscles of the rotator cuff. J Bone Joint Surg Br 91(12):1587-1593

47. Montenegro KR, Cruzat V, Carlessi R, Newsholme P (2019) Mechanisms of vitamin D action in skeletal muscle. Nutr Res Rev 32(2):192-204

48. Dzik KP, Kaczor JJ (2019) Mechanisms of vitamin D on skeletal muscle function: oxidative stress, energy metabolism and anabolic state. Eur J Appl Physiol 119(4):825-839

49. RedzicM,LewisRM, Thomas DT(2013) Relationship between 25-hydoxyvitamin D, muscle strength, and incidence of injury in healthy adults: a systematic review. Nutr Res 33(4):251-258

50. Sale C, Elliott-Sale KJ (2019) Nutrition and athlete bone health. Sports Med 49(Suppl 2):139-151

51. Frost HM (1987) Bone "mass" and the "mechanostat": a proposal. Anat Rec 219(1):1-9

52. Ihle R, Loucks AB (2004) Dose-response relationships between energy availability and bone turnover in young exercising women. JBone Mine Res 19(8):1231-1240

53. Heydenreich J, Kayser B, Schutz Y, Melzer K (2017) Total energy expenditure, energy intake, and body composition in endurance athletes across the training season: a systematic review. Sports Med Open 3(1):8

54. Nazem TG, Ackerman KE (2012) The female athlete triad. Sports Health 4(4):302-311

55. Mountjoy M, Sundgot-Borgen J, Burke L, Carter $S$, Constantini N, Lebrun C, Meyer N, Sherman R, Steffen K, Budgett R, Ljungqvist A (2014) The IOC consensus statement: beyond the Female Athlete Triad-Relative Energy Deficiency in Sport (REDS). Br J Sports Med 48(7):491-497

56. Tenforde AS, Beauchesne AR, Borg-Stein J Hollander K, Mclnnis K, Kotler D, Ackerman KE (2020) Awareness and comfort treating the female athlete triad and relative energy deficency in sport among healthcare providers. Dtsch Z Sportmed 71(3):76-80

57. Tenforde AS, Parziale AL, Popp KL, Ackerman KE (2018) Low Bone mineral density in male athletes is associated with Bone stress injuries at anatomic sites with greater trabecular composition. Am J Sports Med 46(1):30-36

58. Jager R, Kerksick CM, Campbell BI, Cribb PJ, Wells SD, Skwiat TM, Purpura M, Ziegenfuss TN, Ferrando AA, Arent SM, Smith-Ryan AE, Stout JR, Arciero PJ, Ormsbee MJ, Taylor LW, Wilborn CD, Kalman DS, Kreider RB, Willoughby DS, Hoffman JR, Krzykowski JL, Antonio J (2017) International Society of Sports Nutrition Position Stand: protein and exercise. JInt Soc Sports Nutr 14:20

59. Lee EC, Fragala MS, Kavouras SA, Queen RM, Pryor JL, Casa DJ (2017) Biomarkers in sports and exercise: tracking health, performance, and recovery in athletes. J Strength Cond Res 31(10):2920-2937

60. Pedlar CR, Newell J, Lewis NA (2019) Blood Biomarker profiling and monitoring for highperformance physiology and nutrition: current perspectives, limitations and recommendations. Sports Med 49(Suppl 2):185-198

61. Statuta SM, Wood CL, Rollins LK (2020) Common medical concerns of the female athlete. Prim Care 47(1):65-85

62. Neidel $P$, Wolfram $P$, Hotfiel $T$, Engelhardt $M$, Koch R, Lee G, Zwingenberger S (2019) Cross-sectional investigation of stress fractures in German elite triathletes. Sports (Basel) 7(4):88

63. Toxqui L, Vaquero MP (2015) Chronic iron deficiency as an emerging risk factor for osteoporosis: a hypothesis. Nutrients 7(4):2324-2344

64. Nabhan D, Bielko S, Sinex JA, Surhoff K, Moreau WJ, Schumacher YO, Bahr R, Chapman RF (2019) Serum ferritin distribution in elite athletes. J Sci Med Sport 23(6):554-558

65. Pedlar CR, Brugnara C, Bruinvels G, Burden R(2018) Iron balance and iron supplementation for the female athlete: a practical approach. Eur J Sport Sci 18(2):295-305

66. Grober U, Schmidt J, Kisters K (2015) Magnesium in prevention and therapy. Nutrients 7(9):8199-8226

67. Mammoli F, Castiglioni S, Parenti S, Cappadone C, Farruggia G, lotti S, Davalli P, Maier JAM, Grande A Frassineti $C$ (2019) Magnesium is a key regulator of the balance between osteoclast and osteoblast differentiation in the presence of vitamin $D(3)$. Int J Mol Sci 20(2):385

68. Zhang YJ, Xun PC, Wang R, Mao LJ, He K (2017) Can magnesium enhance exercise performance? Nutrients 9(9):946

69. Cordova A, Mielgo-Ayuso J, Roche E, CaballeroGarcia A, Fernandez-Lazaro D (2019) Impact of magnesium supplementation in muscle damage of professional cyclists competing in a stage race. Nutrients 11(8):1927

70. Ilich JZ, Kerstetter JE (2000) Nutrition in bone health revisited: a story beyond calcium. J Am Coll Nutr 19(6):715-737

71. Micheletti A, Rossi R, Rufini S (2001) Zinc status in athletes: relation to diet and exercise. Sports Med 31(8):577-582

72. Parra M, Stahl S, Hellmann H (2018) Vitamin B(6) and its role in cell metabolism and physiology. Cells 7(7):84

73. Chan YM, Bailey R, O'Connor DL (2013) Folate. Adv Nutr 4(1):123-125

74. Tucker KL, Hannan MT, Qiao N, Jacques PF Selhub J, Cupples LA, Kiel DP (2005) Low plasma vitamin B12 is associated with lower BMD: the Framingham Osteoporosis Study. J Bone Miner Res 20(1):152-158

75. Roman-Garcia P, Quiros-Gonzalez I, Mottram L, Lieben L, Sharan K, Wangwiwatsin A, Tubio J, Lewis K, Wilkinson D, Santhanam B, Sarper N, Clare S, Vassiliou GS, Velagapudi VR, Dougan G,
Yadav VK (2014) Vitamin B(1)(2)-dependent taurine synthesis regulates growth and bone mass. JClin Invest 124(7):2988-3002

76. Cadegiani FA, Kater CE (2019) Basal hormones and biochemical markers as predictors of overtraining syndrome in male athletes: the EROS-BASAL study. JAthl Train 54(8):906-914

77. Lombardo B, Izzo V, Terracciano D, Ranieri A, Mazzaccara C, Fimiani F, Cesaro A, Gentile L, Leggiero E, Pero R, Izzo B, D'Alicandro AC, Ercolini D, D'Alicandro G, Frisso G, Pastore L, Calabro P, Scudiero $O$ (2019) Laboratory medicine: health evaluation in elite athletes. Clin Chem Lab Med 57(10):1450-1473 
Hier steht eine Anzeige.

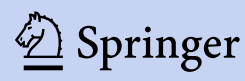

